\title{
Acción colectiva, negociaciones $y$ alianzas tras la Ley de Emergencia Social
}

Collective action, bargaining and alliances behind the Social Emergency Act

\author{
María Maneiro \\ CONICET/IIGG-UBA \\ mariamaneiropinhero@gmail.com \\ Javier Nuñez \\ IIGG-UBA \\ javiern1991@gmail.com
}

Fecha de recepción:

25.8.20

Fecha de aceptación:

11.1.21

\section{Resumen}

El artículo describe el proceso de lucha de las organizaciones de trabajadores de la economía popular en torno a la Ley de Emergencia Social del 2016, así como los resultados institucionales. Su relevancia se encuentra en la excepcionalidad de su aprobación en un contexto de retroceso de luchas populares. El análisis se sustenta en un corpus de notas periodísticas y en documentos del trámite parlamentario. Se distinguen tres períodos: la formación de alianzas y la tematización de la demanda; el trámite parlamentario; y las acciones relacionadas a la implementación. El proceso se caracteriza por la articulación con centrales sindicales y la Iglesia Católica; combinar acciones directas e institucionales; y demandar simultáneamente al Ejecutivo y Legislativo.

Palabras clave: emergencia social - trabajadores de la economía popular - organizaciones sociales acción colectiva - macrismo -Argentina

\section{Abstract}

The article describes the struggle process of the organizations of workers of the popular economy in relation to the Social Emergency Law of 2016, and its institutional results. Its relevance is signed by its exceptionality: its 
approval in a context marked by the regression of popular struggles. The analysis is sustained in a corpus of newspapers articles and the documents related to the legislative procedure. Three moments may be distinguished: the creation of alliances and demand formulation; the legislative process; and the actions related to the implementation. The struggle process is characterized by the articulation with trade unions and the Catholic Church; the combination of direct and institutional actions; and the simultaneous demand to the Legislative and Executive powers.

Key-words: social emergency - workers of popular economy - social movements - collective action - Macri's government - Argentina

\section{Introducción ${ }^{1}$}

Este artículo describe la lucha de las organizaciones de trabajadores desocupados y de la economía popular en los primeros años de la administración presidencial de Mauricio Macri, bajo la Alianza Cambiemos (2015-2019). ${ }^{2}$ Este gobierno tuvo una orientación neoliberal que procuró desarmar una serie de derechos sociales instalados con antelación. Las políticas propiciadas buscaban el disciplinamiento de los trabajadores y los movimientos populares (Rebón 2019). Sin embargo, en este artículo nos queremos detener en una experiencia que matiza esta afirmación, mostrando un caso de lucha exitosa. El análisis propuesto se focaliza en la demanda y aprobación de una legislación de Emergencia Social para los trabajadores de la economía popular. Como se verá en el artículo, la aprobación de esta Ley se enlaza a una modalidad particular de gestión de la asistencia social durante estos años.

Entendemos que este proceso de lucha tiene tres características particulares. La primera es la articulación que desde un inicio establecen las organizaciones demandantes con la Iglesia Católica y posteriormente los intentos sistemáticos de vinculación con las centrales sindicales, incluso con la CGT (Confederación General del Trabajo) tradicionalmente reacia a este tipo de interacción. La segunda es la combinación y articulación de formas de acción directas -por fuera de las instituciones hegemónicas (Pérez y Rebón 2012)-, con formas de acción directa pero dentro de las instituciones hegemónicas y negociaciones en esas instituciones. La tercera es la modulación de la demanda de las organizaciones de trabajadores desocupados dirigidas tanto al Poder Ejecutivo como al Legislativo; en este último sentido se puede decir que el Legislativo funciona como mediador y órgano de presión hacia el Ejecutivo. 
Tal como se irá desarrollando a lo largo del trabajo, entendemos que cada una de las tres características pueden ser leídas como una actualización de aprendizajes, memorias y desplazamientos que fueron produciendo las organizaciones en su devenir. Es así como, la hábil gestión de alianzas, el uso amplio y adecuado de formatos diferenciales de lucha y la capacidad de traducir las demandas en negociaciones bifrontes con las diversas jurisdicciones de los poderes del Estado constituyen elementos que sólo resultan inteligibles a la luz de una mirada más amplia que la que se enfoca en este artículo.

El proceso de lucha es descripto a partir de una periodización que contiene tres momentos. Durante el primer periodo se establece la articulación entre las tres organizaciones centrales de este proceso y se le da entidad a la demanda del proyecto de Ley de Emergencia Social.El segundo momento -en el cual el proyecto de ley es aprobado con modificaciones significativas- se caracteriza por una fuerte interacción con los poderes del Estado. Finalmente, el tercer período se identifica con las luchas enfocadas en la reglamentación de la Ley Emergencia Social en la cual aparecen otras organizaciones de menor porte. Los interrogantes que ordenan la periodización buscan brindar mayores conocimientos a la relación entre el sujeto, el formato de acción en la acción y la respuesta institucional. La hipótesis que se contrasta es la clásica relación inversa entre acciones disruptivas y negociaciones institucionales; matices relevantes del caso justifican la revisión detallada.

Para el desarrollo de este estudio se contó con dos tipos de materiales empíricos. Por un lado, las acciones colectivas de los movimientos de trabajadores de la economía popular fueron registradas en una base de 213 noticias publicadas en periódicos nacionales (Vid Apéndice). El rango temporal de esas notas se extiende entre agosto de 2016 y marzo del 2017. Por el otro lado, se abordaron los documentos propios del trámite legislativo de la Emergencia Social, en vistas a reconocer cómo las negociaciones entre los movimientos y el gobierno se plasmaron en resultados institucionales. Finalmente se revisó la bibliografia que ha trabajado de este tema.

\section{A modo de contexto}

El triunfo de la Alianza Cambiemos en las elecciones del 2015 tuvo una impronta fuertemente regresiva en relación a los derechos de los trabajadores. La agenda propuesta incluía una transformación de la reglamentación laboral y previsional; según Rebón (2019) los trabajadores constituyeron el eje principal de la resistencia. Con demandas principalmente defensivas, el año 2017 fue récord en huelgas (MTSS 2017). Sin embargo, antes de ello, resulta relevante analizar la lucha de las organizaciones sociales y de la economía popular. La llegada de la nueva coalición de gobierno alteró la relación de las organizaciones de trabajadores de la economía popular con los poderes del Estado. 
En lo que respecta a la administración de la política, el cambio de gobierno no sólo implicó una modificación de elenco de funcionarios y una transformación en la modalidad de gestión, sino también la salida de la gestión estatal -a la que habían accedido durante el kirchnerismo- de una serie de referentes de las organizaciones sociales. ${ }^{3}$ No obstante, a pesar de que el nuevo gobierno impulsó iniciativas de corte neoliberal en materia de política laboral y en términos de modelo económico, no implementó recortes en los montos de los programas de asistencia, que cumplían un rol paliativo de la situación social, aunque fomentó una revisión de sus criterios y modos de organización (Hudson 2020). ${ }^{4}$

La doble necesidad de recomponer los ingresos de los trabajadores de la economía popular y de recuperar el lugar de interlocutores del Estado marca los orígenes de la demanda por la Ley de Emergencia Social. La instalación del reclamo, la presión por su aprobación, las negociaciones con los poderes públicos, la articulación con las centrales sindicales y con la Iglesia Católica, así como los resultados institucionales de la Ley serán analizados en este trabajo.

En este proceso de lucha, tres sujetos se presentan como los más dinámicos: la Central de Trabajadores de la Economía Popular (CTEP), Barrios de Pie (BdP) y la Corriente Clasista y Combativa (CCC).

La CTEP, surgida en 2011, se fundó con la meta de constituirse como una organización gremial de los trabajadores informales. ${ }^{5}$ Entre las organizaciones que la conforman asume primacía el Movimiento Evita (ME), organización lanzada en 2006 en la convergencia de organizaciones sociales kirchneristas. El ME excede a la CTEP y tiene correlato en organizaciones político-electorales que se fueron distanciando del entonces Frente para la Victoria hegemonizado por el kirchnerismo (Longa, 2016, 2019). Esta organización tuvo una fuerte participación en programas socio-laborales durante las dos presidencias de Cristina Fernández de Kirchner (2007-2011, 2011-2015) sobre todo por su relevancia en la puesta en marcha y la ejecución del Programa Ingreso Social con Trabajo “Argentina Trabaja” (PRIST-AT) en 2009; también fue la organización social de mayor vinculación con la gestión gubernamental de la Alianza Cambiemos (Longa, 2019). Otros participantes en la CTEP son: el Movimiento de Trabajadores Excluidos (MTE), la cooperativa textil La Alameda, el Movimiento Nacional de Empresas Recuperadas por los Trabajadores (MNER), el Movimiento Popular la Dignidad (MPLD), el Movimiento Nacional Campesino Indígena (MNCI), la Unión de Trabajadores de la Tierra (UTT), la organización social y política Los Pibes, Patria Grande, Seamos Libres y la Garganta Poderosa. Asimismo, la agrupación Misioneros de Franscisco -englobada no sin tensiones en la Iglesia Católica y con cierta vinculación con el Papa Francisco- guarda estrechas relaciones con organizaciones partícipes en la CTEP, en especial con el ME (Forni 2019).

Barrios de Pie es una organización social surgida en el año 2002, ligada a una organización política llamada Corriente Patria Libre, hoy Libres del Sur; sus partícipes habían 
tenido actividad dentro de la Central de Trabajadores Argentinos (CTA) bajo el nombre "CTA de los barrios". Durante la crisis de 2001-2002 BdP tomó este nombre y se distanció de la central sindical mencionada. Fue acercándose a la base del gobierno kirchnerista durante el año 2004, separándose en 2008. Tanto dentro del oficialismo como de la oposición ha tenido una acción sumamente relevante. Durante los años en que formó parte de la base del gobierno nacional su participación en programas socioproductivos fue importante, destacándose la actividad en el programa "Manos a la Obra" en los primeros años del gobierno del presidente Néstor Kirchner (2003-2007). Con posterioridad, luego de su alejamiento, constituye la organización más activa en la lucha por el ingreso en el Programa Ingreso Social con Trabajo Argentina Trabaja durante los años 2010-2011 (Gradin 2016, 2017; Maneiro, 2018).

La Corriente Clasista y Combativa, vinculada al Partido Comunista Revolucionario (PCR), surgió a principios de los años noventa, manteniendo en principio alianzas con algunos sectores de la CGT y la CTA y profundizando un eje de trabajo territorial y con desocupados. A fines de esa década extendió su rama territorial, articulando con la Federación de Tierra yVivienda (FTV) y teniendo un fuerte peso en zonas del municipio bonaerense de La Matanza (Svampa y Pereyra, 2009). Desde 2003 ha ido distanciándose de la FTV y constituyó una de las organizaciones sociales más combativas durante todos los gobiernos kirchneristas, sin que esto impidiera su colaboración con las diversas propuestas de tipo socio-productivas que se fueron poniendo en marcha en esos años y su ingreso a ellas (Maneiro, 2012, 2018).

Una periodización del devenir de estas organizaciones excede los objetivos de este trabajo. No obstante, se contemplarán tres fases que contienen características divergentes. Un primer momento comprende el surgimiento de estas organizaciones y se extiende hasta la crisis de comienzo de siglo: es durante este período que en una doble vía entre el trabajo territorial y la acción directa se pone en agenda el problema de la desocupación; es también durante este período que las organizaciones sociales comienzan a gestionar programas de empleo y asistencia social. Las tentativas de minimizar el peso político de los intendentes ligados al entramado duhaldista fue un aspecto sustancial para abrir el espacio de gestión a las organizaciones sociales (Svampa y Pereyra 2009; Maneiro 2012).

Un segundo momento se desarrolla durante los gobiernos kirchneristas. Si bien la característica central del período fue el mayor acercamiento, llegando a la inclusión de referentes de las organizaciones a diferentes instancias gubernamentales, este proceso tuvo fuertes matices; en la bibliografia se han suscitado acalorados debates en torno a la "cooptación"y la "integración" de estas organizaciones. Las tres organizaciones que nos ocupan tuvieron trayectorias diferenciadas. Al comienzo del gobierno de Néstor Kirchner la CCC era considerada una organización "semi dura" que luego devino abiertamente opositora. En cambio, BdP y el ME se fueron sumando prontamente, con algunas diferencias cronológicas, 
y se distanciaron durante el gobierno de Cristina Férnandez de Kirchner. Sea como fuere, tanto el origen "piquetero" como esta impronta estatal han dejado una huella en las organizaciones que contribuyó a “traducir” (Hudson 2018) en términos de negociaciones y modalidades de gestión demandas específicas (Perelmiter 2016).

El programa "Manos a la Obra" constituyó el primer eslabón de una serie de iniciativas de articulación entre las demandas de las organizaciones sociales, el trabajo asociativo y las políticas públicas; los programas “Argentina Trabaja” y "Ellas Hacen”, con la impronta del Ministerio de Desarrollo Social, constituye el momento cúlmine en torno a esta tentativa. El "asociacionismo forzado" ha sido un eje de debate en los trabajos académicos (Hudson 2018). El gobierno de la Alianza Cambiemos abrió una nueva etapa en el devenir de estas organizaciones, cuyo proceso de lucha brinda elementos para la caracterización del período.

Las tres organizaciones más dinámicas aparecen en los medios de comunicación como el "Triunvirato Piquetero"; la alusión al trío mediante esta calificación demarca un nudo de sentidos que actualiza la memoria de lucha de la primera fase en el devenir de las organizaciones de trabajadores desocupados en la década de 1990, específicamente por su referencia el "piquete", como el formato más utilizado en sus acciones de protesta. Sin embargo, como ya se dijo, en algunos momentos puntuales se pueden identificar otras organizaciones que no se incluyen en las mencionadas, pero que también participaban de la contienda y las negociaciones: la Iglesia Católica y las centrales de trabajadores -la CGT y las dos Centrales de Trabajadores Argentinos (CTA). ${ }^{6}$

Acerca de la Iglesia, es menester tomar en consideración el efecto de poder que inscribe la participación más o menos solapada de la autoridad papal respecto de dotar de legitimidad a los reclamos. En relación a las centrales sindicales, el acompañamiento se da en un doble sentido: así como las organizaciones de trabajadores desocupados y de la economía popular participan de algunas de las acciones de la CGT y las CTA, esas centrales también formaron parte de los reclamos de las organizaciones, en especial en los primeros dos períodos de este proceso de lucha. Dicha articulación supone un profundo cambio respecto a la modalidad histórica de acción de la CGT, clásicamente distante de los reclamos de trabajadores desocupados; consignar este acercamiento es uno de los principales resultados de este proceso de investigación. Es en este sentido que se puede vislumbrar un acercamiento de esta última a las demandas que desde mediados los años 1990 -en medio de una creciente tasa de desempleo- fueron acompañadas por la CTA; en torno a ello, la CTA, ya desde sus orígenes, contuvo una vertiente de trabajadores desocupados.

Durante el proceso que aquí se describe, estas organizaciones se aglutinaron en torno a la demanda por la Ley de Emergencia Social. En su proyecto original, dicha norma suponía dos elementos centrales que habrán de atravesar los reclamos desde la formulación inicial de la demanda hasta las modalidades de reglamentación de su 
implementación: 1) la creación de un millón de puestos de trabajo a través de un nuevo programa de "Ingreso Social con Trabajo"; 2) la conformación de un Consejo de la Economía Popular que regularía la transformación de los programas de empleo en un nuevo "Salario Social Complementario" y definiría el monto de dicho programa.

Si bien corresponde al Poder Ejecutivo Nacional la implementación de la ley -a través del Ministerio de Desarrollo Social, a cargo de la ministra Carolina Stanley-, estrictamente la demanda tiene como principal referente al Poder Legislativo. La negociación con el Congreso implicó una novedad en la modulación que adquieren los reclamos del movimiento de trabajadores de la economía popular y da cuenta de la especificidad de la estructura de oportunidades políticas propia de los primeros dos años de la presidencia de Mauricio Macri. En efecto, las mayorías del Parlamento Nacional se reconfiguraron sustantivamente tras las elecciones de 2015. Si bien en la Cámara de Senadores el bloque del Frente para la Victoria (FPV) siguió teniendo mayoría, la Alianza Cambiemos tuvo éxito en lograr la aprobación de sensibles proyectos, aprovechando las divisiones internas del peronismo -entre sectores más cercanos al kirchnerismo y otros más próximos al nuevo gobierno- y llevando a cabo negociaciones específicas con los gobernadores provinciales (Corral y Forresti 2018). De esta manera, si bien la falta de mayoría del entonces oficialismo lo exponía a la posible aprobación de proyectos de ley que resultaran adversos, el gobierno tenía la capacidad de influir considerablemente en el trámite legislativo. Al mismo tiempo, la interpelación al Congreso no puede verse al margen de negociaciones con el Ejecutivo, que debe reglamentar la ley y tiene capacidad de vetarla. Este pivote constituye otro elemento nodal respecto de los resultados de esta investigación

La transformación del reclamo de un sustento a la economía popular abrió una nueva forma de entender las políticas hacia el sector. La modalidad no era necesariamente colectiva ni cooperativa, sino que sumaba a todo aquel trabajador cuyo ingreso no le permitiera su subsistencia.

Se mencionó más arriba que la CGT modificó su rol previo, en tanto en este período acompaña y promueve la demanda de las organizaciones de trabajadores desocupados y la economía informal. Cabe decir, como elemento coyuntural que puede colaborar en el entendimiento de este acercamiento, que la Ley de Emergencia Social fue tratada por el Congreso al mismo tiempo que una reforma en el impuesto a las ganancias a trabajadores de mayores niveles de ingresos -reclamo particularmente importante para la CGT. Sin embargo, también puede ser una evidencia de transformaciones más permanentes, que se expresan en los dirigentes y que ponen parcialmente en crisis la representación corporativa estrecha de los trabajadores organizados en sindicatos. Esto solamente se podrá evaluar con el correr del tiempo.

Así, la demanda de las organizaciones de trabajadores de la economía popular se encuentra envuelta en una constelación formada por diferentes arenas de negociación: de 
las organizaciones con el Gobierno -directamente y a través del avance del proyecto en el Congreso-; de las centrales sindicales, que incluyen su apoyo junto a otros reclamos; y de los senadores de la oposición con el Ejecutivo. La novedad, en relación a otros momentos históricos, no yace, ciertamente, como se ha podido entrever en la breve periodización antes expuesta, en la existencia de relaciones entre organizaciones de la economía popular y el Ministerio de Desarrollo Social, sino en cómo la interpelación al Congreso media en esas negociaciones. Así, las organizaciones intercalan acciones directas, más o menos disruptivas, con acciones colectivas de negociación institucional con dos poderes del Estado. Al mismo tiempo, desde la perspectiva del oficialismo, la interlocución con las organizaciones sociales permitió la implementación de programas sociales al margen de los intendentes municipales, en su mayoría de la oposición al gobierno macrista (mostrando cierto paralelismo, ahora magnificado, con las iniciativas de la Alianza Unión Cívica Radical-Frapaso a fines del siglo pasado). De acuerdo a un autor, la institucionalización de esa relación gobierno-organizaciones de la economía popular- también fue entendida por los funcionarios del gobierno como un modo de contención de la protesta social (Hudson, 2020).

\section{Precisiones teórico-metodológicas}

El análisis de este proceso se sustenta -por una parte- en el universo de noticias publicadas por los diarios nacionales relativas a las acciones realizadas por las organizaciones de trabajadores desocupados y de la economía popular que tienen como norte la demanda de la aprobación y/o la reglamentación de la Ley de Emergencia Social desde agosto de 2016 hasta marzo de 2017. Se han rastreado todos los diarios de porte nacional y se seleccionaron todas las noticias que remitían a estas organizaciones y/o a la Ley de Emergencia social. Luego se realizó un recorte de aquellas pertinentes (algunas de las noticias no se ligaban a este proceso de lucha o suponían apenas columnas de opinión). Finalmente, se arribó a un universo de 213 notas. Si bien se incluyeron artículos de los diarios La Nación, Clarín y Página/12, el tratamiento más exhaustivo del proceso fue encontrado en el diario La Nación. Así, la confección de la base de datos se centró en la cobertura de esta fuente, con notas publicadas entre el 9 de julio de 2016 y el 3 de mayo de 2017.

El recorte temporal está justificado porque durante el mes de agosto de 2016 se realizó la primera acción cuyo contenido se asocia a la demanda de esta Ley (a pesar de que ésta aún no aparece enunciada) y en marzo de 2017 se decretó la reglamentación de la misma.

El trabajo de sistematización de la información fue de tipo cualitativo. Después de la lectura exhaustiva del conjunto de notas, se elaboró una base de datos en la que se registraron todas las acciones producidas por las organizaciones, con este recurso se logró elaborar la cronología que se presenta a posteriori. Tal como se puede ver en la tabla anexa para cada caso se registraron las siguientes dimensiones: el formato de la acción, la/s demanda/s, 
sujeto o institución a la que se re realiza la demanda,la/s organizacion/es que la llevaron a cabo, el lugar de la acción, la fecha y las alianzas que se lograron para tal actividad.

Con este material se produjo un escueto pero exhaustivo catálogo de eventos. A partir de la definición de Tilly (2002) entendemos al catálogo de eventos como un conjunto delimitado de acciones compiladas mediante procedimientos uniformes. Tilly, al trabajar con la larga duración y con catálogos enormes, empleó formas cuantitativas. Sin embargo por la limitada cantidad de acciones que componen nuestro catálogo (44 acciones) la forma de registro y de análisis fue de tipo cualitativa.

La unidad de registro en estos catálogos es la acción contenciosa; de acuerdo a Tilly acciones contenciosas son las que poseen un carácter colectivo y suponen demandas cuyo destinatario y responsable respecto de la resolución del problema planteado son los poderes de gobierno del Estado (Tilly 1978). Asimismo, las acciones se encuentran históricamente situadas, actualizando memorias que se ligan a las mutaciones institucionales acaecidas (Tilly, 2000). Este vínculo, tanto entre lo pretérito y lo actual, como entre la acción directa y la institucional, constituye un punto de partida para el presente trabajo.

Suponemos que las memorias contenciosas de estas organizaciones han contribuido a la eficacia, la combatividad selectiva y la masividad de las acciones que describimos a partir de nuestro catálogo; a su vez, consideramos que las experiencias previas de gestión y negociación de demandas han sido centrales en la cualidad del repertorio más institucionalmente centrado. Nuestra definición de acción, por todo ello, matiza la noción "outsider" de los sujetos de la acción, pues las organizaciones que generan estos episodios han instituido modalidades de gestión, tramitación y negociación de demandas en su trayectoria previa. ${ }^{7}$

Nuestro catálogo comprende un repertorio de acciones de diversa cualidad. Se compone tanto de acciones directas, es decir que se producen por fuera de las instituciones de representación vigentes. Estas asumen formatos diversos, con diferente nivel de combatividad y de distancia institucional: los cortes de vías públicas, los acampes y las ollas populares en las calles y avenidas constituyen los formatos más distantes de las modalidades institucionales. Las reuniones interorganizacionales, las movilizaciones, los actos públicos sin bloqueo de tránsito, etc. comprenden una modalidad intermedia de acción contenciosa dentro de los límites institucionales vigentes y, finalmente, se registraron acciones emprendidas por las organizaciones dentro de las instituciones hegemónicas: encuentros y reuniones con representantes y funcionarios, presentaciones de proyectos, etc. (vid.Anexo). El contrapunto entre estas modalidades diferenciales constituye un aspecto de interés dentro de nuestro proceso de investigación y se liga a los momentos diferenciales en la periodización propuesta.

En segundo término, este artículo, se basa en un abordaje exhaustivo y comparativo de los documentos que sustentan la Ley de Emergencia Social, tomando en cuenta el 
proyecto, la ley finalmente aprobada y su decreto de reglamentación. Se implementó un análisis cualitativo del contenido bajo la procura de encontrar continuidades y modificaciones entre los mismos. Se entiende que la acción de las organizaciones en pugna fue nodal en relación a los avances y los límites de los resultados normativos alcanzados.

Finalmente se articularon interpretativamente los dos tipos de fuentes, para interrogarse sobre las modalidades en que la acción de las organizaciones de trabajadores de la economía popular afecta los tiempos y los contenidos que adquiere la reglamentación resultante.

\section{Descripción del proceso}

Como se mencionó en la introducción, la lucha en torno a la aprobación y puesta en marcha de la Ley de Emergencia Social supuso un proceso de acción llevado adelante por las organizaciones de trabajadores desocupados y de la economía popular. Dicho proceso se encuentra atravesado por dos características que lo diferencian de otras dinámicas previas. Entendemos que la experiencia institucional de las organizaciones que lideran este proceso produjo una transformación en sus modalidades de lucha enfatizando la importancia no sólo de las acciones directas, tan relevantes en los últimos años de la década de 1990 y los primeros de este siglo, sino también la negociación institucional y el cabildeo legislativo tan practicado en la pos-crisis. La combinación de acciones directas e institucionales, que involucran negociaciones simultáneas con los poderes Ejecutivo y Legislativo, primero; y la formación de una serie de alianzas con centrales sindicales, la Iglesia Católica y algunas fuerzas políticas, como segundo aspecto, caracterizan a este proceso.

La periodización presentada segmenta la disputa por la Ley de Emergencia Social en tres momentos. Los hitos que marcan el tránsito de un período a otro están dados por la media sanción original del Senado -el 16 de noviembre- y por la aprobación final de la ley -a mediados de diciembre del 2016. A continuación, se describirán en detalle las acciones producidas en cada uno de ellos y los devenires que va presentando el proyecto; con estos elementos se caracterizará cada uno de los tres momentos.

\section{Primer período: la elaboración y formalización de la demanda}

Este primer momento se desarrolla desde agosto hasta mediados de noviembre 2016 y se caracteriza por la confluencia de una serie de organizaciones hacia la elaboración de la demanda, la aproximación a los representantes legislativos y la formalización del proyecto de ley para enviar al Poder Legislativo. Es el período más extenso de esta periodización y contiene cinco acciones directas por fuera de los canales institucionales; dieciséis acciones colectivas semi-institucionales y cuatro acciones de negociación institucional. Las acciones directas se presentan en los bordes del período: iniciando la demanda pública, al comienzo y apurando su tratamiento, al finalizar; estas últimas, por ello se producen 
contemporáneamente con las acciones institucionales evidenciando una modalidad polar y bifronte de la acción. Las movilizaciones, actos y demás formas de acción colectiva dentro de los parámetros legales se mantienen a lo largo del período. Sólo una acción fue realizada por una organización externa al "Triunvirato de San Cayetano".

El rito iniciático se produce con la peregrinación al Santuario de San Cayetano en el barrio portño de Liniers, cuyo momento central estuvo dado por la homilía brindada a las 11 hs. por el Arzobispo de Buenos Aires, Mario Poli -quien sucedió a Jorge Bergoglio al ser éste elegido Papa y se considera una voz autorizada para expresar el enfoque papal-. Tal celebración se desarrolla todos los 7 de agosto, día en que se conmemora dicho santo, su objeto es pedir (y/o agradecer) al santo patrono del pan y del trabajo y tiene un particular significado para los trabajadores desde la icónica peregrinación de la CGT liderada por Saúl Ubaldini a comienzos de 1981.

Según relatos de los participantes recogidos por la prensa la fila para ingresar al santuario alcanzó ochocientos metros durante la jornada completa con una estimación de un millón de personas (Ladrón de Guevara 2016). Sin embargo, durante esta jornada específica no se desarrolló sólo la tradicional visita espontánea al santuario sino que participaron varias organizaciones sociales. Éstas realizaron, con posterioridad a la homilía, una movilización desde Liniers hasta Plaza de Mayo. Allí, la presencia de la institución eclesiástica fue menor a la que se encontraba en el santuario aunque se identificaban inscripciones que remitían a "Los misioneros de Francisco" y a "La Alameda", ambas instituciones fuertemente entroncadas con las organizaciones católicas. Pese a ello, los sujetos principales de esta marcha fueron aquellos que habrían de confluir en la demanda de la Ley Emergencia Social: BdP, CTEP y CCC. En esta ocasión aún no aparece mencionada la Ley de Emergencia Social; el pedido de estas organizaciones fue que se buscara una solución para los desocupados y la economía popular. Las demandas contenían, sin embargo, un requerimiento que se iría desarrollando progresivamente hasta culminar en el reclamo por la ley. Por el tipo de acción específica, esta movilización encuentra entre sus aliados directos a la Iglesia Católica; confluyeron también fracciones de una de las CTA y algunos referentes del peronismo y del kirchnerismo.

Si bien esta acción expresa consignas en contra de la política económica y demandas sociolaborales específicas para el sector, su eje parece estar más en la expresividad de la convergencia entre organizaciones diversas y referentes políticos de la oposición. En los debates del Senado previos a la aprobación final de la Ley, la peregrinación a San Cayetano es mencionada, incluso, como el inicio del reclamo. En este sentido, el período comienza en esta confluencia de actores dentro de un marco de demandas en proceso de desarrollo y maduración. La búsqueda de alianzas y solidaridades se observa también en la reunión que las organizaciones sociales realizan ese mismo día con la CGT solicitándole apoyo para las demandas de los trabajadores desocupados y de la economía popular. 
Esta acción inicial continuó a fines del mes de agosto con una reunión de BdP con funcionarios del Ministerio de Trabajo y de la CCC y la CTEP con miembros del Poder Legislativo. Este encuentro se produjo con los senadores Juan Manuel Abal Medina y Miguel Ángel Pichetto (ambos senadores por el entonces Frente para la Victoria) y la diputadaVictoria Donda (Libres del Sur). Esta reunión, en el seno de la principal institución de representación del pueblo, expuso el curso de la transformación de la demanda en torno a un proyecto de ley. Este momento de acción se complementó con un acampe de BdP frente al Ministerio de Trabajo, del 23 al 24 de agosto, produciendo un bloqueo de la Avenida N. L Alem de casi 19 hs. ${ }^{8}$ Como resultado directo del acampe, Barrios de Pie consiguió una reunión con funcionarios de la cartera laboral que se comprometieron a incluir a la organización en dos nuevos programas sociales. La bifrontalidad tanto respecto del tipo de acciones, como el doble destinatario emerge con claridad en este tándem. Una reunión con los representantes legislativos, un encuentro con funcionarios ejecutivos y un acampe frente a un ministerio nacional; un compendio del repertorio y su pivote entre los poderes del Estado parecen configurar el momento final de los antecedentes respecto de la elaboración del proyecto de ley. Desde la acción que le sigue la demanda de la Ley de Emergencia Social ya aparece formulada con claridad.

A comienzos del mes de septiembre, BdP organizó cien ollas populares contra la pobreza. La magnitud de esta acción merece ser atendida, en cuanto conlleva una fuerte denuncia respecto del problema de la pobreza y el hambre y en su realización brinda alimento a miles de personas. La relevancia de esta actividad es insoslayable mostrando el incipiente papel dinamizador y radicalizador de la acción colectiva de la organización BdP, que actúa tanto en forma independiente como articulada a las otras dos.

Al día siguiente las tres organizaciones sociales que conformaban el "Triunvirato" se reunieron con la CGT; de acuerdo a un cronista el encuentro "estuvo guiado por las coincidencias por primera vez en décadas". La CGT tomó nota de la necesidad "de representar a los desocupados y a los trabajadores informales" y se comprometió a sumar las demandas de las organizaciones sociales entre los puntos centrales del nuevo paro, cuya ocurrencia se definiría hacia finales del mes (Balinotti 2016). Este aspecto constituye el primer eslabón de una alianza singular que se produce en esta lucha y que tendría su punto más relevante en la movilización del 18 de noviembre de 2016.

Un día después, el 9 de septiembre, BdP, la CTEP y la CCC se encuentran con las dos CTA para acrecentar la red de alianzas por la Ley de Emergencia Social. La construcción de la articulación que fue central durante el mes de agosto no había terminado, si no que se superponía a la instalación de la demanda en el espacio público. Ambas CTA coincidían en la necesidad de unificar la acción entre las organizaciones sociales y las organizaciones sindicales y anunciaron una acción de protesta para mediados de mes. 
En ese momento, los senadores del FPV presentaron el proyecto demandado por las organizaciones de trabajadores desocupados y de la economía popular solicitando la declaración por ley de la Emergencia Social por un año, el aumento de la AUH, la creación de puestos de trabajo para cooperativistas y el establecimiento del Consejo de la Economía Popular y el Salario Social Complementario (CEPSSC). ${ }^{9}$ Las acciones previas muestran así un primer resultado, logrando la respuesta positiva de un grupo de senadores que inició formalmente el proceso institucional de tratamiento del proyecto de ley. Dos de los senadores que originalmente presentaron el proyecto integraban parte de la bancada del FPV próxima al ME, a los que se sumó otro legislador de un espacio progresista (GEN), Finalmente, fueron 24 los senadores que acompañaron con su firma el proyecto.

La creación de un millón de puestos de trabajo destacaba entre los elementos centrales del proyecto. Por otro lado, referentes de las organizaciones que impulsaron la emergencia consideraron que sentaría las bases de una Obra Social de Trabajadores de la Economía Popular. Sin embargo esta protección no tiene mención explícita en el texto del proyecto, pese a que formó parte del debate público. Estos dos elementos -la creación de un millón de puestos de trabajo y la Obra Social- no formarán parte de la ley finalmente aprobada (Hopp, 2017). El proyecto no incluía fuentes específicas de financiamiento. En la discusión parlamentaria, en cambio, se propuso la financiación mediante la creación y reposición de algunas tasas e impuestos. Se estimó que la emergencia supondría un costo de 40.000 millones de pesos.

El proceso de búsqueda de alianzas y solidaridades continuó. Días más tarde BdP, la CTEP y la CCC se reunieron con la CGT, la Iglesia y varias organizaciones del interior del país para solicitar colaboración en la sensibilización respecto de la situación social con miras a que el gobierno del Estado promoviera alguna política especial para los trabajadores de la economía popular.

Para fines del mes de septiembre, con el ingreso de otras organizaciones sociales menos propensas a la negociación estatal, que realizaron un acampe en la Plaza de Mayo, se puso en evidencia una fase más amplia y activa en torno a las acciones de protesta. El Frente de Organizaciones en Lucha (FOL), el MTD Aníbal Verón, el Movimiento Teresa Rodríguez, el Frente PopularVíctor Choque, la Federación de Organizaciones de Base (FOB),Votamos Luchar, la Agrupación Clasista Lucha y Trabajo y el Movimiento de Resistencia Popular (MRP), entre otros, agrupados en la Asociación Gremial de Trabajadores Cooperativos Autogestionados y Precarizados (Agtcap) reclamaron trabajar ocho horas diarias y percibir un ingreso correspondiente. También demandaron la realización de una paritaria social y la actualización de los montos de los programas de empleo. En este sentido, cabe decir que estas agrupaciones mientras se incluían en la demanda del "Triunvirato", formulaban otros reclamos que no formaban parte del menú de peticiones de las organizaciones más importantes. Ese mismo día BdP realiza 
una movilización al Congreso Nacional y junto a la CCC y a la CTEP desarrollaron una serie de asambleas públicas en el conurbano.

Esta fase continuó durante la primera mitad del mes de octubre con variadas acciones de protesta. El 6 de octubre BdP, la CCC y la CTEP, el Frente Popular Darío Santillán (FPDS) y otras organizaciones de desocupados de raigambre territorial realizaron ollas populares en distintas ciudades del país en demanda del tratamiento del proyecto de ley de Emergencia Social por el Congreso Nacional. A mediados del mes BdP y el FPDS realizaron una caravana con el objetivo de denunciar la desigualdad en la Ciudad de Buenos Aires y solicitar la Emergencia Social. Durante este mes se produjeron encuentros con las dos CTA y la CGT para requerir sus apoyos a dicha demanda. Ambas CTA anunciaron una movilización por este reclamo; las organizaciones sociales expresaron su decepción por la falta de recepción del reclamo por parte de la CGT, pero pocos días después, la misma CGT, bajo la articulación de Juan Carlos Schmid, principal promotor de la vinculación entre las organizaciones y la central, anunció su participación en la movilización del 18 de noviembre para demandar la sanción de la Ley de Emergencia Social. Pese a todo, no se logró el llamado a huelga general, tan esperado por las dos CTA y las organizaciones sociales. ${ }^{10}$

A mediados de mes, la CTEP, la CCC y BdP -acompañadas de representantes de la Iglesia- se reunieron con la Ministra de Desarrollo Social Carolina Stanley y acordaron formar una mesa de negociación para tratar los reclamos de las organizaciones (entre ellos un bono de $\$ 1.000$ pesos por AUH y el aguinaldo social para cooperativistas) y se demandó el apoyo del Poder Ejecutivo para permitir el tratamiento parlamentario de la Emergencia Social. Para fin del mes las organizaciones se reunieron con los diputados del arco opositor, participando representantes del FPV, del Frente Renovador (FR escisión del FPV ocurrida hacia las elecciones legislativas del 2013), del Bloque Justicialista (escisión posterior a la elección presidencial del 2015), socialistas, Libres del Sur -la organización política asociada a BdP-y Proyecto Sur.

El proceso de mayor dinamismo y de relativa ampliación de los sujetos de la acción de protesta parece haber colaborado en fechar una serie de acuerdos. Se inició entonces hacia mediados de septiembre y comienzos de octubre un proceso de mayor actividad en la acción colectiva de tipo directa y, a posteriori, la apertura de procesos institucionales de negociación. La protesta se puso en evidencia como un canal instituyente de las políticas para el sector.

Los receptores de las acciones fueron tanto el Poder Ejecutivo, principalmente el Ministerio de Desarrollo Social, como los miembros opositores del Poder Legislativo, con quienes ya habían existido mayores encuentros de negociación. La bifrontalidad es constatada durante todo este primer período y parece haber continuado en los momentos subsiguientes. Desde el punto de vista del gobierno, se planteaban diferentes negociaciones simultáneas pero ligadas entre sí: así, ante la posibilidad de un paro de la CGT, el Poder Ejecutivo anunció una 
serie de encuentros con las organizaciones sociales y sindicales, entre las que se incluye a los trabajadores de la economía popular. Desde la perspectiva de estas organizaciones las negociaciones constituían un carril paralelo al del trámite parlamentario de la ley. La maduración de la articulación de la relación y la tan esperada confirmación de un acto de la CGT en la cual se tomase como uno de los ejes el reclamo de la Ley de Emergencia Social fue el evento que puso fin a este primer período mostrando la efectividad de la masificación y la articulación de los trabajadores de la economía popular con la principal confederación gremial del país.

\section{Segundo período: trámite legislativo y acción directa}

En los meses de noviembre y diciembre -lapso que ocupa el segundo período- las dinámicas del momento anterior se profundizaron. Primero, la interpelación al Poder Legislativo se incrementó conforme avanzaba el trámite parlamentario de la ley. Segundo, también se hicieron más frecuentes las instancias de negociación con el Poder Ejecutivo con miras a evitar el posible veto presidencial y avanzar en pautas en torno a la reglamentación. Tercero, los acuerdos con otras organizaciones más allá de las tres principales se concretaron en acciones colectivas conjuntas y/o articuladas.

Una primera constatación a partir de estos tres ejes es la polaridad de las acciones: mientras el "Triunvirato" se orienta hacia actividades institucionales de negociación con los diferentes poderes, también actualiza su matriz más combativa al realizar acciones más osadas, al tiempo que organizaciones externas al trío llevan a cabo acciones directas por fuera del entramado institucional. Sólo se constata una acción semi-institucional que, sin embargo es la principal acción de todo el proceso de lucha por su masividad y su eficacia: el acto del 18 de noviembre de 2016.

El itinerario completo y resumido de la fase incluye la media sanción del proyecto de ley por la Cámara de Senadores el día 16 de noviembre, el posterior acto en reclamo de la aprobación de la Ley por la Cámara de Diputados dos días más tarde y el acuerdo entre las organizaciones y el gobierno nacional, una semana después de la aprobación original por Senadores. El proyecto se aprobó en la Cámara de Diputados (6 de diciembre) con importantes modificaciones; fue remitido al Senado, quien lo aprobó el día 15.

Si bien durante este período las principales organizaciones participaron de acciones que excedían la demanda de la ley (como parte de la articulación con otros sectores, en particular las CTA), los ritmos de la movilización se encontraban marcados por el avance del proyecto de Ley de Emergencia Social. A diferencia de los otros períodos, todas las acciones llevadas a cabo por la CTEP, la CCC y BdP fueron realizadas en conjunto, poniéndose en evidencia el momento más unitario del trío. Paralelamente, hacia el final del período, organizaciones de menor volumen comenzaron a realizar reclamos relacionados con la futura implementación de la Emergencia Social, cuestión que marcará el período siguiente. 
En términos de la descripción del proceso, el trámite parlamentario se aceleró durante noviembre 2016. El tercer día del mes, el proyecto fue aprobado en comisión con el apoyo de los bloques del FPV y Generación para un Encuentro Nacional (GEN). El avance en el legislativo fue de la mano de una interrupción de las negociaciones entre las organizaciones y el Ministerio de Desarrollo Social. El recurso a la acción directa de tipo semi institucional se tradujo en el anuncio de dos movilizaciones importantes; la primera a la Plaza de Mayo el día 5, y por ello remite al período anterior, y la segunda, verdaderamente monumental, dirigida al Congreso Nacional el día 18. Ambas acciones son de tipo semiinstitucional en la gradación que hemos propuesto, destacando una vez más la relación inversa entre la masividad y las formas semi- institucionales en la inflexión entre el primer y segundo período de este estudio; las protestas masivas asumieron un formato de acción menos radicalizado, articulándose con repertorios inscriptos dentro de la legalidad.

El acto realizado el 5 de noviembre en Plaza de Mayo puso de relieve la porosidad de los bordes de nuestra periodización. Convocado por las organizaciones sociales y ambas CTA, en él se denunció la insuficiencia del bono social de $\$ 1.000$ acordado entre el gobierno nacional y la CGT, se reclamó la realización de un paro general y se demandó la sanción de la Ley de Emergencia Social. Este acto que, según sus organizadores, convocó a 50 mil personas, fue muy importante para expresar un piso movilizatorio del arco socio-laboral opositor, constituyendo un doble referente, a saber: la CGT, a la que se presionaba para activar los reclamos, y el Poder Ejecutivo a quien se le reclamaba mejores propuestas para morigerar la pérdida de valor adquisitivo del salario. Es en este intermedio que se cuela la demanda de emergencia social que aglutina a los participantes de la actividad.

En este contexto la Cámara de Senadores dio media sanción al proyecto de ley original. El 17 de noviembre, mientras desde el gobierno nacional se sugería la posibilidad de un veto al proyecto aún antes de ser aprobado, las organizaciones confirmaron, desde la CGT, la convocatoria al acto para el día siguiente. La convocatoria contó con el acompañamiento de esta confederación obrera, de las dos CTA, del “Triunvirato de San Cayetano" y otras organizaciones sociales.

El acto del 18 de noviembre se erige como la actividad movilizatoria más convocante de todo el período en estudio, constituyendo asimismo el hito de mayor expresividad en relación a la articulación de las organizaciones sociales con las centrales sindicales en general pero fundamentalmente con la histórica CGT. El acto de ese día, en el centro porteño, fue multitudinario: de acuerdo a sus organizadores reunió 200 mil personas. El respaldo de la CGT a la demanda de la Ley de Emergencia Social adquirió una dimensión activa y corpórea, pasando de la solidaridad discursiva y el acompañamiento en las negociaciones a la puesta en marcha de la red movilizatoria al servicio de la demanda mencionada. La CGT estaba dirigida por un triunvirato y dos de los tres triunviros de la CGT fueron oradores en el acto junto con representantes de la CCC, BdP y la CTEP. Los discursos exigieron el 
tratamiento de la ley antes del receso parlamentario y rechazaron el posible veto. En este marco, los dirigentes de la CGT realizaron cierta autocrítica respecto al rol de la misma frente a los trabajadores desocupados y la economía popular.

Tras este masivo acto, la interpelación al Legislativo y la acción directa fueron continuados por varias jornadas de negociación entre el Ministerio de Desarrollo Social, y las organizaciones de trabajadores desocupados y de la economía popular, representantes de la Iglesia Católica y de la oposición. Además del tratamiento del proyecto de ley en Diputados, las organizaciones demandaron un bono de $\$ 500$ para cada beneficiario de la AUH. El acuerdo alcanzado destrabó el trámite parlamentario, aunque supuso significativas alteraciones al proyecto original.

Resulta interesante la comparación del proyecto original y el que finalmente fue aprobado, en tanto las distancias entre ellos dan cuenta del producto de la negociación entre las organizaciones y el Poder Ejecutivo.

Como se mencionó antes, el acuerdo dejó de lado la creación de un millón de puestos de trabajo a través de cooperativas; tampoco incluyó la obra social de trabajadores de la economía popular. Si bien estos cambios son centrales, no son los únicos. En línea con el proyecto original, la ley conformó el CEPSSC, aunque alteró su composición pasando de dos representantes del Ejecutivo y tres por las organizaciones a una paridad de 3 integrantes de cada tipo (agregando un delegado del Ministerio de Hacienda a los de Desarrollo Social y Trabajo). Al igual que en el proyecto, las organizaciones que pueden participar del CEPSSC deben integrar un registro creado por el Ministerio de Desarrollo Social. Si bien la Ley precisa su rol de encargado de definir los lineamientos para cumplir con los objetivos de la emergencia, quita la referencia explícita del proyecto al establecimiento de una canasta básica que debería equivaler al Salario Social Complementario (SSC). A su vez, en esta nueva versión se extendió tiempo de implementación del Consejo de 30 a 90 días.

En relación a la implementación del SSC, la Ley trasladó su definición última del Consejo al Poder Ejecutivo y eliminó el plazo de 180 días para su establecimiento. Aun así, el CEPSSC conservó como tarea la progresiva transformación de los programas sociales en salario social complementario (SSC). Asimismo, se eliminó el aumento del 15\% en el monto mensual de la AUH. Finalmente, el proyecto aprobado estableció el monto de $\$ 30.000$ millones de pesos a invertir hasta el 2019 para cumplir con la Emergencia Social. Este monto no podría salir de partidas previamente dedicadas a "servicios sociales".

La negociación destrabó el tratamiento de la ley -con modificaciones- en la Cámara de Diputados. Con motivo de esa votación, la CTEP, la CCC y BdP instalaron ollas populares y marcharon al Congreso el 6 de diciembre, día de la media sanción. El Senado convirtió la Emergencia Social en ley el día 15 de diciembre. La votación fue ampliamente favorable al proyecto en ambas ocasiones. La vinculación entre la demanda al Ejecutivo y la 
interpelación al Legislativo es evidente en el trámite final de la Ley: el acuerdo se plasmó directamente en el texto aprobado y las bancadas oficialistas acompañaron el voto afirmativo.

Antes de la aprobación -todavía dentro de los límites temporales de este período- comenzaron a producirse movilizaciones por parte de organizaciones por fuera de la CCC, CTEP y BdP. El $1^{\circ}$ de diciembre realizaron un bloqueo total de la Avenida 9 de Julio, reclamando participación en los acuerdos que llevaban a la sanción del proyecto y, posteriormente, en su implementación. Esta dinámica iba a tener mayor importancia en la siguiente etapa, cuando las demandas se concentrasen en la reglamentación de la ley.

Yendo desde la masividad hasta las protestas más audaces, con el respaldo de la CGT y evidenciando una fuerte impronta bifronte que ponderaba la negociación pero utilizaba la protesta para hacer oír su voz, presionar y apurar los tiempos, el proyecto de Ley de Emergencia Social, significativamente modificado, fue sancionado.

\section{Tercer período: Disputas por la implementación de la Ley}

La sanción de la Ley de Emergencia Social puso fin al reclamo simultáneo a los poderes Legislativo y Ejecutivo e inauguró la presión por la implementación de la misma, en la que el Ministerio de Desarrollo Social se convirtió en el único interlocutor. Llamativamente en este período se producen menos noticias sobre negociaciones institucionales, una mayor proporción de acciones directas y una ampliación de la red de organizaciones participantes. Los ejes de las demandas fueron dobles: por un lado se esperaba incidir en los tiempos de la reglamentación: por el otro las organizaciones externas al "Triunvirato" buscaban presionar para ampliar la red organizacional de agrupaciones participantes. Todo eso ligado a que la eficacia de una Ley puede variar sensiblemente según cómo se produzca su implementación.

El texto finalmente aprobado contenía dos cuestiones sustanciales en torno a las acciones de reclamo por la implementación. Por un lado, el período en el que el Poder Ejecutivo debía reglamentar la Ley se extendió de 30 a 90 días, abriendo la incógnita respecto a cuál sería la actitud del gobierno meses después de las movilizaciones que presionaron la negociación. Por otro lado, la ley establecía la inclusión de representantes de las organizaciones en la agencia encargada del control del SSC: ocupar los tres lugares del CEPSSC destinados a las organizaciones constituye un modo de ser reconocido como interlocutor legítimo del Ministerio. La posibilidad de integrar dicho ámbito dependía de un registro creado por la ley. ${ }^{11}$ Por todo ello no es sorprendente que en este tercer período se produjeran más acciones de parte de organizaciones que no integraban el llamado "Triunvirato de San Cateyano”, en reclamo de participación en la implementación de la emergencia.

Así otras organizaciones por fuera de la CTEP, la CCC y BdP, como el FPDS, cobraron cierto protagonismo al desarrollar acciones colectivas directas demandando la 
participación en la implementación de la emergencia social. También realizaron protestas el Polo Obrero (PO), Quebracho y el Frente por el Trabajo y la Dignidad Milagro Sala. Estas otras organizaciones lucharían por incorporarse tras la sanción, abriendo un nuevo proceso de debate acerca de la amplitud democrática de la propuesta conseguida.

Estas acciones colectivas directas continuaron en los últimos días de diciembre expresando un aumento recortado en el tiempo de la cantidad de acciones y de las organizaciones participantes. Durante el mes de enero se produce un reflujo de la acción que finaliza con un corte de avenidas y una movilización por la ciudad dirigida por el FPDS y otras organizaciones sociales; $y$ a partir del mes de febrero, vuelven a cobrar protagonismo estas otras agrupaciones (el FPDS, el PO, el Frente de Organizaciones en Lucha-FOL), al tiempo que la CTEP, la CCC y BdP renuevan el reclamo de reglamentación de la ley al Ejecutivo.

De todos modos, entre la sanción de la ley en diciembre 2016 y su reglamentación en marzo del año siguiente, las acciones colectivas fueron más esporádicas que en los períodos anteriores. La articulación con las centrales obreras continuó, en el marco del paro general que la CGT realizaría en el mes de abril, pero este evento ya queda fuera de nuestro recorte temporal.

El 21 de febrero la CTEP, la CCC y BdP instalaron ollas populares en diferentes puntos de la Ciudad de Buenos Aires, para luego movilizarse al Obelisco. En esa ocasión BdP asumió la voz cantante en el reclamo por la implementación, mientras desde la CTEP se amenazó con un plan de lucha contra la política económica del gobierno. La protesta tuvo como demanda inmediata el rechazo al recorte de programas sociales por parte del Ministerio de Trabajo y la reglamentación de la Emergencia Social. Dos días después, la CCC volvió a movilizarse al Obelisco porteño con similares demandas.

El 11 de marzo de 2017, el Poder Ejecutivo reglamentó la Ley de Emergencia Social de modo parcial, mediante el Decreto 159/2017. En dicho decreto se precisan las funciones del CEPSSC, incluyendo los mecanismos de inscripción, elegibilidad y regularización de quienes accedan al Salario Social Complementario y la posibilidad de formular propuestas no vinculantes al Poder Ejecutivo para concretar los objetivos de la Ley. Asimismo, facultó a los miembros titulares del Consejo a incorporar en calidad de delegados a miembros de otras organizaciones, así como a convocar a representantes de miembros de organizaciones de la sociedad civil con interés en la temática. En cambio, el decreto guarda silencio respecto al financiamiento de la norma, habilitando sólo al CEPSSC a solicitar informes presupuestarios. La conformación inicial de los integrantes del Consejo incluyó a un representante de cada una de las tres organizaciones más importantes.

Posteriormente esas organizaciones denunciaron en forma conjunta dilaciones en la implementación de la norma y anunciaron la realización de cortes de calle el 15 de marzo de 2017. Al mismo tiempo, el PO y el FOL llevaron adelante un acampe frente al 
Ministerio de Desarrollo Social, exigiendo ser incorporados a los programas de empleo. Así, en términos de los dos componentes de la demanda del período, mencionados más arriba, las tres organizaciones principales fueron exitosas en lograr una primera implementación vía el decreto reglamentario, en los tiempos previstos por la ley. En cambio, la inclusión de otras agrupaciones permaneció incierta.

La actualización de las acciones de calles, en su forma directa y/o semi institucionalizada, volvió a explicitar ausencia de cánones institucionales para enmarcar las negociaciones, incluso luego de sancionada la ley.A partir de este momento el Consejo reglamentado podría abrir una fase diferente en torno a las formas de canalización de las demandas, pero lamentablemente la escasa actividad del mismo no mostró una productividad de relevancia.

La reglamentación parcial dejó preocupadas a las organizaciones. La ausencia de un mecanismo de financiamiento hacía prever dificultades severas para la implementación, aunque Hudson (2018) afirma que el presupuesto estaba asegurado. Una serie de interrogantes se abren acerca de cuáles fueron los fundamentos acerca de por qué en un contexto recesivo se logra un relativo éxito en una demanda de fracciones fuertemente pauperizadas.

\section{Consideraciones finales}

El artículo que presentamos describe y analiza el proceso de formulación, aprobación y reglamentación de la Ley de Emergencia Social a partir de una lente particular, a saber, el papel de las organizaciones sociales como formuladoras, demandantes, promotoras y sujetos beligerantes dentro del sistema político. En este sentido se pudieron reconocer las principales organizaciones que lo llevaron a cabo, las solidaridades y confluencias que se construyeron en el devenir. Así también consideramos haber logrado mostrar la permanente conjunción de formas de lucha y negociación que estas organizaciones promueven, utilizando tanto acciones directas como modalidades institucionales de negociación y demanda.

Los períodos que se han descrito pueden resumirse como un primer momento de elaboración de la demanda y de construcción de las principales alianzas y de formulación del proyecto; luego, un segundo momento de presentación formal y de solidificación de las solidaridades con las confederaciones gremiales, profundización de la acción colectiva y reformulación selectiva del proyecto en vista a su aprobación final.Y un tercer momento de demanda de reglamentación y de preocupación respecto de la dilación y la parcialidad de esta. En este último período participaron también otras organizaciones menos ligadas a las instituciones hegemónicas que quedaron por fuera del CEPSSC. Cabe decir que la institución del CEPSSC, más allá de su escasa relevancia fáctica, constituye un nuevo eslabón de inscripción de las organizaciones dentro del sistema político. 
Es importante destacar que este proceso de lucha se vio articulado primeramente con la Iglesia, bajo la venia de allegados al Papa Francisco. El papel de este último en la puesta en agenda de la Emergencia Social constituyó un elemento importante. Por otra parte, y a medida que el proceso avanzaba, se registraron tentativas de mayor acercamiento entre las organizaciones de desocupados y las centrales sindicales. En este sentido la articulación y el apoyo de la CGT constituyó uno de los elementos más novedosos. Dilucidar cuán profunda y duradera podría ser esta articulación es una interrogante sobre la que se deberá volver en nuevos trabajos. Sea como fuere, la ruptura -incluso momentánea- con el modelo corporativo segmentado de protección estrecha (Etchemendy y Collier 2007), es un ingrediente que debe ser resaltado.

Una vez más se ha de mostrar que la acción contenciosa resulta un potente recurso para la satisfacción de demandas, la capacidad de actualización de las memorias de acción de calles constituye una característica que identifica a estas organizaciones. Empero, ésta no se manifiesta en forma pura sino a partir de diversas bifrontalidades: 1) acción directa más rupturista en los momentos en los cuales hay un quiebre de la negociación o como recurso de las organizaciones que quedan por fuera del juego institucional; 2) acción directa dentro de los parámetros de la legalidad cuando las alianzas son más sólidas, más amplias y las acciones son más masivas; 3) negociaciones institucionales en un juego de pivote entre el Poder Ejecutivo y el Legislativo, utilizando a este último y sobre todo al Senado aún hegemonizado por la oposición, como centro de poder de lobby.

La mayor relevancia de acciones institucionales podría indicar su vinculación con la participación en las instituciones del gobierno del Estado en la gestión anterior al gobierno de la alianza Cambiemos. Dicha participación supondría una aproximación a saberes específicos. Una nueva actualización de memorias parece, entonces, estar poniéndose en juego. Sin embargo, este aspecto merecería nuevas indagaciones.

Mucho se ha escrito en los estudios sobre acción colectiva acerca del ciclo de la protesta. Este trabajo, por el contrario, estudia el ciclo de una demanda que comienza como una serie de peticiones y en su formulación como proyecto de ley va articulando a tres organizaciones sociales como las grandes promotoras de la misma. El proceso, asimismo, se ve transformado posteriormente como resultado de las negociaciones enmarcadas en la tramitación parlamentaria, para finalmente retomar selectiva y parcialmente las demandas de estos grupos. Por último, un nuevo trastrocamiento se desarrolla a partir de la reglamentación de la norma que contempla algunos de los aspectos de la misma pero sin indicar las fuentes de financiamiento. Este prisma de estudio permite observar los procesos de transformación de las demandas situadas en las articulaciones y las disputas entre los sujetos que participan del campo. Es así como se inserta en el conjunto de estudios acerca de la "traducción" institucional de demandas sociales. La trama de estos itinerarios de traducción resulta de central interés para estudiar las formas de la politicidad democrática más allá de las modalidades de representación formal. Esperamos haber contribuido con este trabajo a este tipo de investigaciones. 


\begin{tabular}{|c|c|c|c|c|c|c|c|}
\hline \multicolumn{8}{|c|}{ ACCIONES DE PROTESTA E INSTITUCIONALES EN POS DE LA EMERGENCIA SOCIAL } \\
\hline Núm. & Fecha & Lugar & $\begin{array}{l}\text { Sujeto de la } \\
\text { acción }\end{array}$ & Formato & Aliados & Demanda & Antagonistas \\
\hline 1 & 07/08/2016 & $\begin{array}{l}\text { San Cayetano } \\
\text { (Liniers) } \\
\text { / Plaza de } \\
\text { Mayo }\end{array}$ & $\begin{array}{l}\text { Mov. Evita / } \\
\text { CTEP / } \\
\text { CCC / Barrios } \\
\text { de Pie }\end{array}$ & $\begin{array}{l}\text { Marcha Liniers/ } \\
\text { Plaza de Mayo } \\
\text { Acto en Plaza de } \\
\text { Mayo }\end{array}$ & $\begin{array}{l}\text { CTA / CGT } \\
\text { Fundación La } \\
\text { Alameda } \\
\text { Iglesia católica } \\
\text { Dirigentes del } \\
\text { peronismo/ } \\
\text { kirchnerismo }\end{array}$ & $\begin{array}{l}\text { Rechazo a } \\
\text { medidas de ajuste }\end{array}$ & Gobierno nacional \\
\hline 2 & $24 / 08 / 2016$ & $\begin{array}{l}\text { Ministerio } \\
\text { de Trabajo }\end{array}$ & Barrios de Pie & $\begin{array}{l}\text { Acampe frente } \\
\text { al Ministerio de } \\
\text { trabajo }\end{array}$ & & $\begin{array}{l}\text { "Comité de crisis" } \\
\text { con empresarios } \\
\text { y organizaciones } \\
\text { religiosas } \\
\text { Fortalecimiento } \\
\text { de programas de } \\
\text { empleo }\end{array}$ & $\begin{array}{l}\text { Gobierno nacional } \\
\text { / Ministerio de } \\
\text { Trabajo }\end{array}$ \\
\hline 3 & 07/08/2016 & Sede CGT & $\begin{array}{l}\text { Barrios de Pie / } \\
\text { CCC / CTEP / } \\
\text { Mov. Evita }\end{array}$ & $\begin{array}{l}\text { Reunión de } \\
\text { dirigentes de } \\
\text { movimientos } \\
\text { sociales con } \\
\text { dirigentes de la } \\
\text { CGT }\end{array}$ & CGT & $\begin{array}{l}\text { Situación socio- } \\
\text { económica de } \\
\text { desocupados e } \\
\text { informales }\end{array}$ & Gobierno nacional \\
\hline 4 & 08/09/2016 & $\begin{array}{l}\text { CABA } \\
\text { Callao y } \\
\text { Corrientes } \\
\text { CCK }\end{array}$ & Barrios de Pie & $\begin{array}{l}\text { Ollas Populares } \\
\text { Protesta }\end{array}$ & & $\begin{array}{l}\text { "100 ollas } \\
\text { populares contra } \\
\text { la pobreza" }\end{array}$ & $\begin{array}{l}\text { Gobierno de la } \\
\text { Ciudad de Buenos } \\
\text { Aires }\end{array}$ \\
\hline 5 & 08/09/2016 & Sede CGT & $\begin{array}{l}\text { Barrios de Pie / } \\
\text { CCC / CTEP / } \\
\text { Mov. Evita }\end{array}$ & $\begin{array}{l}\text { Reunión de las } \\
\text { organizaciones } \\
\text { con Triunvirato } \\
\text { de la CGT }\end{array}$ & & $\begin{array}{l}\text { "Situación } \\
\text { socio-económica } \\
\text { de desocupados e } \\
\text { informales" }\end{array}$ & Gobierno nacional \\
\hline 6 & 09/09/2016 & $\begin{array}{l}\text { Sede CTA } \\
\text { Autónoma }\end{array}$ & $\begin{array}{l}\text { Barrios de Pie / } \\
\text { CCC / CTEP / } \\
\text { Mov. Evita }\end{array}$ & $\begin{array}{l}\text { Reunión de } \\
\text { dirigientes de } \\
\text { movimientos sociales } \\
\text { con dirigientes de las } \\
\text { dos CTA }\end{array}$ & CTA (ambas) & $\begin{array}{l}\text { Ley de } \\
\text { emergencia social } \\
\text { y salario social } \\
\text { complementario } \\
\text { para cooperativistas }\end{array}$ & Gobierno nacional \\
\hline 7 & $15 / 09 / 2016$ & $\begin{array}{l}\text { Congreso } \\
\text { Nacional }\end{array}$ & $\begin{array}{l}\text { Barrios de Pie / } \\
\text { CCC / CTEP / } \\
\text { Mov. Evita }\end{array}$ & $\begin{array}{l}\text { Presentación } \\
\text { legislativa del } \\
\text { proyecto de } \\
\text { emergencia social }\end{array}$ & Senadores FPV & $\begin{array}{l}\text { Declaración de } \\
\text { emergencia por un } \\
\text { año, aumento de } \\
\text { AUH y creación } \\
\text { de puestos de } \\
\text { trabajo para } \\
\text { cooperativistas. } \\
\text { Creación de } \\
\text { Consejo de la } \\
\text { Economia Popular }\end{array}$ & Gobierno nacional \\
\hline 8 & $24 / 09 / 2016$ & Sede CGT & $\begin{array}{l}\text { Barrios de Pie / } \\
\text { CCC / CTEP }\end{array}$ & $\begin{array}{l}\text { Encuentro con } \\
\text { la Iglesia en el } \\
\text { marco de una } \\
\text { "jornada de } \\
\text { reflexión sobre } \\
\text { tierra, techo y } \\
\text { trabajo" }\end{array}$ & $\begin{array}{l}\text { Iglesia, CGT, } \\
\text { Distintos } \\
\text { movimientos } \\
\text { sociales del } \\
\text { Interior }\end{array}$ & $\begin{array}{l}\text { "No busca crítica } \\
\text { al gobierno sino } \\
\text { interpelarlo sobre } \\
\text { la situación" }\end{array}$ & Gobierno nacional \\
\hline 9 & $27 / 09 / 2016$ & $\begin{array}{l}\text { Plaza de } \\
\text { Mayo }\end{array}$ & $\begin{array}{l}\text { AGTCAP, (FOL), el } \\
\text { MTD AníbalVerón, } \\
\text { MTR, el Frente } \\
\text { PopularVíctor } \\
\text { Choque, (FOB), } \\
\text { Votamos Luchar, la } \\
\text { Agrupación Clasista } \\
\text { Lucha y Trabajo y } \\
\text { (MRP) }\end{array}$ & $\begin{array}{l}\text { Acampe y ollas } \\
\text { populares }\end{array}$ & & $\begin{array}{l}\text { Puestos de } \\
\text { trabajo para } \\
\text { cooperativistas, } \\
\text { paritaria social, } \\
\text { bono especial de } \\
\text { fin de año } \\
\text { También } \\
\text { menciona: } \\
\text { créditos y tierras }\end{array}$ & Gobierno nacional \\
\hline 10 & $27 / 09 / 2016$ & $\begin{array}{l}\text { Congreso } \\
\text { Nacional }\end{array}$ & Barrios de pie & $\begin{array}{l}\text { Movilización al } \\
\text { Congreso }\end{array}$ & & $\begin{array}{l}\text { Declaración } \\
\text { de emergencia } \\
\text { social }\end{array}$ & Gobierno nacional \\
\hline
\end{tabular}




\begin{tabular}{|c|c|c|c|c|c|c|c|}
\hline 11 & $30 / 09 / 2016$ & $\begin{array}{l}\text { Gran Buenos } \\
\text { Aires }\end{array}$ & $\begin{array}{l}\text { Barrios de pie / } \\
\text { CCC / CTEP }\end{array}$ & $\begin{array}{l}\text { Asambleas en } \\
\text { puntos céntricos } \\
\text { del conurbano } \\
\text { (La Matanza, } \\
\text { Avellaneda y } \\
\text { Florencio Varela) }\end{array}$ & & $\begin{array}{l}\text { Sanción de ley de } \\
\text { emergencia social } \\
\text { Salario social } \\
\text { complementario } \\
\text { Puestos de } \\
\text { trabajo para } \\
\text { cooperativistas }\end{array}$ & Gobierno nacional \\
\hline 12 & 06/10/2016 & $\begin{array}{l}\text { Capital, } \\
\text { Córdoba, } \\
\text { Tucumán, } \\
\text { Salta, Chaco, } \\
\text { San Luis, } \\
\text { Neuquén y } \\
\text { Formosa }\end{array}$ & $\begin{array}{l}\text { Barrios de pie / } \\
\text { CCC / CTEP, } \\
\text { Mov. Evita } \\
\text { Fte. popular Dario } \\
\text { Santillán }\end{array}$ & Ollas populares & Senadores FPV & $\begin{array}{l}\text { Ley de } \\
\text { emergencia } \\
\text { social }\end{array}$ & $\begin{array}{l}\text { Gobierno nacional } \\
\text { (ejecutivo)/ } \\
\text { Congreso }\end{array}$ \\
\hline 13 & $11 / 10 / 2016$ & & CTEP & $\begin{array}{l}\text { CTEP (Grabois) } \\
\text { dice que de } \\
\text { movilizarse las } \\
\text { CTA, ellos también } \\
\text { participaran de esa } \\
\text { movilización }\end{array}$ & CTA & $\begin{array}{l}\text { Ley de } \\
\text { emergencia } \\
\text { social }\end{array}$ & Gobierno nacional \\
\hline 14 & $14 / 10 / 2016$ & $\begin{array}{l}\text { Capital (del } \\
\text { Obelisco a } \\
\text { Lugano) }\end{array}$ & $\begin{array}{l}\text { Barrios de pie / } \\
\text { Fte. popular Dario } \\
\text { Santillán }\end{array}$ & $\begin{array}{l}\text { Caravana entre } \\
\text { el Obelisco y la } \\
\text { Villa olímpica en } \\
\text { construcción en } \\
\text { Villa Lugano. Ollas } \\
\text { populares y acto }\end{array}$ & & $\begin{array}{l}\text { Replicar Ley de } \\
\text { emergencia social } \\
\text { en Capital }\end{array}$ & $\begin{array}{l}\text { Gobierno de la } \\
\text { Ciudad de Buenos } \\
\text { Aires }\end{array}$ \\
\hline 15 & $20 / 10 / 2017$ & $\begin{array}{l}\text { Ministerio } \\
\text { de Desarrollo } \\
\text { Social }\end{array}$ & $\begin{array}{l}\text { Barrios de pie/ } \\
\text { CCC / CTEP }\end{array}$ & $\begin{array}{l}\text { Reunión con } \\
\text { Carolina Stanley }\end{array}$ & & $\begin{array}{l}\text { Acordar mesa de } \\
\text { negociación de } \\
\text { reclamos de las } \\
\text { organizaciones } \\
\text { Ley de } \\
\text { emergencia social }\end{array}$ & $\begin{array}{l}\text { Ministerio de } \\
\text { Desarrollo Social }\end{array}$ \\
\hline 16 & $21 / 10 / 2016$ & Hotel Bauen & $\begin{array}{l}\text { Barrios de pie / } \\
\text { CCC / CTEP }\end{array}$ & $\begin{array}{l}\text { Las CTA anuncían } \\
\text { movilización. } \\
\text { Los movimientos } \\
\text { participan del } \\
\text { anuncio y prometen } \\
\text { acompañar. }\end{array}$ & CTA & $\begin{array}{l}\text { Ampliación de } \\
\text { bono de } \$ 1000 \\
\text { pesos ofrecido } \\
\text { y refuerzo a } \\
\text { programas de } \\
\text { empleo }\end{array}$ & $\begin{array}{l}\text { Gobierno } \\
\text { nacional. }\end{array}$ \\
\hline 17 & $27 / 10 / 2016$ & Sede CGT & $\begin{array}{l}\text { Barrios de pie / } \\
\text { CCC / CTEP }\end{array}$ & $\begin{array}{l}\text { Reunión con } \\
\text { CGT para mostrar } \\
\text { apoyo a ley de } \\
\text { emergencia social }\end{array}$ & CGT & $\begin{array}{l}\text { Tratamiento } \\
\text { de ley de } \\
\text { emergencia social } \\
\text { en el Congreso }\end{array}$ & $\begin{array}{l}\text { Gobierno } \\
\text { nacional. }\end{array}$ \\
\hline 18 & $27 / 10 / 2016$ & $\begin{array}{l}\text { Congreso } \\
\text { Nacional }\end{array}$ & $\begin{array}{l}\text { Barrios de pie / } \\
\text { CCC / CTEP }\end{array}$ & $\begin{array}{l}\text { Reunión de } \\
\text { diputados de } \\
\text { diferentes bancadas } \\
\text { con dirigentes de } \\
\text { los movimientos } \\
\text { para anunciar } \\
\text { apoyo a la ley de } \\
\text { emergencia social }\end{array}$ & $\begin{array}{l}\text { Diputados FPV, } \\
\text { FR, Bloque } \\
\text { justicialista, } \\
\text { socialistas, } \\
\text { Libres del Sur, } \\
\text { Proyecto sur }\end{array}$ & $\begin{array}{l}\text { Tratamiento } \\
\text { de ley de } \\
\text { emergencia social } \\
\text { en el Congreso }\end{array}$ & Gobierno nacional \\
\hline 19 & $28 / 10 / 2016$ & $\begin{array}{l}\text { Autopista } \\
\text { Buenos Aires } \\
\text { / La Plata }\end{array}$ & $\begin{array}{l}\text { Movimiento Social } \\
\text { " } 22 \text { de Agosto } \\
\text { Carlos Almiron" }\end{array}$ & $\begin{array}{l}\text { Corte en } \\
\text { Autopista }\end{array}$ & & $\begin{array}{l}\text { Reclamo de } \\
\text { planes sociales }\end{array}$ & Gobierno nacional \\
\hline 20 & $03 / 11 / 2016$ & $\begin{array}{l}\text { Congreso } \\
\text { Nacional }\end{array}$ & & $\begin{array}{l}\text { Dictamen positivo } \\
\text { en comisión del } \\
\text { Senado }\end{array}$ & $\begin{array}{l}\text { Bloques de } \\
\text { senadores FPV, } \\
\text { GEN y UCR }\end{array}$ & $\begin{array}{l}\text { Aprobación } \\
\text { de ley de } \\
\text { emergencia } \\
\text { social }\end{array}$ & \\
\hline
\end{tabular}




\begin{tabular}{|c|c|c|c|c|c|c|c|}
\hline 21 & $05 / 11 / 2016$ & $\begin{array}{l}\text { Plaza de } \\
\text { mayo }\end{array}$ & $\begin{array}{l}\text { Barrios de pie / } \\
\text { CCC / CTEP }\end{array}$ & $\begin{array}{l}\text { Marcha de las } \\
\text { CTA a Plaza de } \\
\text { Mayo, acompañada } \\
\text { entre otros por } \\
\text { los movimientos } \\
\text { piqueteros, como } \\
\text { anticipo de un } \\
\text { paro contra el } \\
\text { gobierno }\end{array}$ & Las dos CTA & $\begin{array}{l}\text { Aprobación } \\
\text { de ley de } \\
\text { emergencia } \\
\text { social }\end{array}$ & Gobierno nacional \\
\hline 22 & $09 / 11 / 2016$ & & $\begin{array}{l}\text { Barrios de pie / } \\
\text { CCC / CTEP }\end{array}$ & $\begin{array}{l}\text { Anuncio de } \\
\text { movilización } \\
\text { para el } 18 / 11 \\
\text { por ruptura en } \\
\text { negociaciones } \\
\text { con el gobierno }\end{array}$ & & $\begin{array}{l}\text { Bono de fin } \\
\text { de año } \\
\text { Aprobación } \\
\text { de ley de } \\
\text { emergencia } \\
\text { social }\end{array}$ & Gobierno nacional \\
\hline 23 & $16 / 11 / 2016$ & $\begin{array}{l}\text { Congreso } \\
\text { Nacional }\end{array}$ & $\begin{array}{l}\text { Barrios de pie / } \\
\text { CCC / CTEP }\end{array}$ & $\begin{array}{l}\text { Media sanción en el } \\
\text { Senado a la ley de } \\
\text { emergencia social }\end{array}$ & $\begin{array}{l}\text { Senadores } \\
\text { FPV y otras } \\
\text { bancadas }\end{array}$ & $\begin{array}{l}\text { Aprobación de } \\
\text { ley de emergencia } \\
\text { social }\end{array}$ & Gobierno nacional \\
\hline 24 & $17 / 11 / 2016$ & Sede CGT & $\begin{array}{l}\text { Barrios de pie / } \\
\text { CCC / CTEP }\end{array}$ & $\begin{array}{l}\text { Anuncio de } \\
\text { movilización al } \\
\text { Congreso para el } \\
\text { día siguiente junto } \\
\text { con CGT y otras } \\
\text { organizaciones }\end{array}$ & $\begin{array}{l}\text { CGT, FA, } \\
\text { Cgera, } \\
\text { movimientos } \\
\text { campesinos }\end{array}$ & $\begin{array}{l}\text { No al posible } \\
\text { veto a la ley } \\
\text { de emergencia } \\
\text { social }\end{array}$ & Gobierno nacional \\
\hline 25 & $18 / 11 / 2016$ & $\begin{array}{l}\text { Plaza del } \\
\text { Congreso }\end{array}$ & $\begin{array}{l}\text { Barrios de pie / } \\
\text { CCC / CTEP }\end{array}$ & $\begin{array}{l}\text { Manifestación } \\
\text { y acto frente al } \\
\text { Congreso }\end{array}$ & CGT & $\begin{array}{l}\text { Aprobación de } \\
\text { ley de emergencia } \\
\text { social }\end{array}$ & Gobierno nacional \\
\hline 26 & $21 / 11 / 2016$ & $\begin{array}{l}\text { Ministerio } \\
\text { de Desarrollo } \\
\text { Social }\end{array}$ & $\begin{array}{l}\text { Barrios de pie / } \\
\text { CCC / CTEP }\end{array}$ & $\begin{array}{l}\text { Reunión con } \\
\text { Stanley para } \\
\text { discutir bono y } \\
\text { emergencia social }\end{array}$ & Iglesia católica & $\begin{array}{l}\text { Bono de fin de } \\
\text { año de } \$ 500 \text { por } \\
\text { hijo con AUH } \\
\text { Aprobación de } \\
\text { ley de emergencia } \\
\text { social }\end{array}$ & Gobierno nacional \\
\hline 27 & $22-23 / 11 / 2016$ & $\begin{array}{l}\text { Ministerio } \\
\text { de } \\
\text { Desarrollo } \\
\text { Social }\end{array}$ & $\begin{array}{l}\text { Barrios de pie / } \\
\text { CCC / CTEP }\end{array}$ & $\begin{array}{l}\text { Reuniones con } \\
\text { funcionarios de } \\
\text { gobierno hasta } \\
\text { acuerdo }\end{array}$ & $\begin{array}{l}\text { Diputados } \\
\text { de distintos } \\
\text { bloques de } \\
\text { oposición }\end{array}$ & $\begin{array}{l}\text { Bono de fin } \\
\text { de año } \\
\text { Ley de } \\
\text { emergencia social } \\
\text { Consejo de la } \\
\text { Economia popular }\end{array}$ & Gobierno nacional \\
\hline 28 & $1 / 12 / 2016$ & $\begin{array}{l}\text { Ministerio } \\
\text { de } \\
\text { Desarrollo } \\
\text { Social }\end{array}$ & $\begin{array}{l}\text { Movimiento } \\
\text { Anibal Verón / } \\
\text { Quebracho / otras } \\
\text { organizaciones }\end{array}$ & $\begin{array}{l}\text { Corte en la } 9 \text { de } \\
\text { julio y marcha al } \\
\text { Ministerio }\end{array}$ & & $\begin{array}{l}\text { Incoporación en } \\
\text { acuerdos acerca } \\
\text { de emergencia } \\
\text { social }\end{array}$ & Gobierno nacional \\
\hline 29 & $6 / 12 / 2016$ & $\begin{array}{l}\text { Cámara de } \\
\text { Diputados } \\
\text { (Congreso } \\
\text { Nacional) }\end{array}$ & $\begin{array}{l}\text { Barrios de pie / } \\
\text { CCC / CTEP }\end{array}$ & $\begin{array}{l}\text { Media sanción } \\
\text { de la Cámara } \\
\text { de Diputados } \\
\text { a la Ley de } \\
\text { emergencia social }\end{array}$ & $\begin{array}{l}\text { Votan a favor } \\
\text { todos los } \\
\text { bloques, menos } \\
\text { FIT y Olmedo }\end{array}$ & $\begin{array}{l}\text { Aprobación } \\
\text { de ley de } \\
\text { emergencia } \\
\text { social }\end{array}$ & Gobierno nacional \\
\hline 30 & $6 / 12 / 2016$ & $\begin{array}{l}\text { Distintos } \\
\text { puntos de } \\
\text { Capital y el } \\
\text { resto del país }\end{array}$ & $\begin{array}{l}\text { Barrios de pie / } \\
\text { CCC / CTEP } \\
\text { Frente Dario } \\
\text { Santillán }\end{array}$ & $\begin{array}{l}\text { Ollas populares } \\
\text { (Barrios de Pie) } \\
\text { Manifestación en } \\
\text { Plaza del Congreso }\end{array}$ & $\begin{array}{l}\text { Diputados } \\
\text { (la nota no } \\
\text { menciona los } \\
\text { bloques que } \\
\text { votaran a favor) }\end{array}$ & $\begin{array}{l}\text { Aprobación de } \\
\text { ley de emergencia } \\
\text { social }\end{array}$ & $\begin{array}{l}\text { Gobierno naciona } \\
\text { Diputados }\end{array}$ \\
\hline 31 & $6 / 12 / 2016$ & $\begin{array}{l}\text { Avenida } 9 \text { de } \\
\text { Julio }\end{array}$ & $\begin{array}{l}\text { Polo Obrero } \\
\text { MST }\end{array}$ & $\begin{array}{l}\text { Bloqueo en Av. } 9 \\
\text { de Julio }\end{array}$ & & $\begin{array}{l}\text { Participación en } \\
\text { ley de emergencia } \\
\text { social }\end{array}$ & Gobierno nacional \\
\hline 32 & $\begin{array}{l}6 / 12 / \\
2016\end{array}$ & $\begin{array}{l}\text { Avenida } \\
\text { Alem }\end{array}$ & $\begin{array}{l}\text { Tendencia } \\
\text { Piquetera } \\
\text { Revolucionaria, } \\
\text { AníbalVerón, } \\
\text { Descamisados, } \\
\text { Miles, Quebracho }\end{array}$ & $\begin{array}{l}\text { Corte de la } \\
\text { Avenida Alem }\end{array}$ & & $\begin{array}{l}\text { Participación } \\
\text { en ley de } \\
\text { emergencia } \\
\text { social }\end{array}$ & Gobierno nacional \\
\hline
\end{tabular}




\begin{tabular}{|c|c|c|c|c|c|c|c|}
\hline 33 & $15 / 12 / 2016$ & $\begin{array}{l}\text { Cámara de } \\
\text { Senadores }\end{array}$ & $\begin{array}{l}\text { Barrios de pie / } \\
\text { CCC / CTEP }\end{array}$ & $\begin{array}{l}\text { Sanción de la Ley } \\
\text { de emergencia } \\
\text { social }\end{array}$ & $\begin{array}{l}\text { Aprobada por } \\
\text { unanimidad ( } 49 \\
\text { votos a favor) }\end{array}$ & $\begin{array}{l}\text { Aprobación de } \\
\text { ley de emergencia } \\
\text { social }\end{array}$ & Gobierno nacional \\
\hline 34 & $17 / 12 / 2016$ & $\begin{array}{l}\text { Facultad de } \\
\text { Ciencias } \\
\text { Sociales } \\
\text { (UBA) }\end{array}$ & $\begin{array}{l}\text { Frente Trabajo y } \\
\text { Dignidad Milagro } \\
\text { Sala (Tupac } \\
\text { Amaru y otras } \\
\text { organizaciones) } \\
\text { Quebracho } \\
\text { Corriente Anibal } \\
\text { Verón } \\
\text { (CNCT) }\end{array}$ & $\begin{array}{l}\text { Primer Congreso } \\
\text { del Frente }\end{array}$ & & $\begin{array}{l}\text { Ingreso al } \\
\text { programa de } \\
\text { ingreso social con } \\
\text { trabajo } \\
\text { Participar de la } \\
\text { mesa de discusión } \\
\text { con el gobierno } \\
\text { sobre la ley de } \\
\text { emergencia social }\end{array}$ & Gobierno nacional \\
\hline 35 & $31 / 1 / 2017$ & $\begin{array}{l}\text { Callao y } \\
\text { Corrientes }\end{array}$ & $\begin{array}{l}\text { Frente popular } \\
\text { Dario Santillán }\end{array}$ & $\begin{array}{l}\text { Corte en Callao y } \\
\text { Corrientes }\end{array}$ & & $\begin{array}{l}\text { Reglamentación } \\
\text { de ley de } \\
\text { emergencia social }\end{array}$ & $\begin{array}{l}\text { Gobierno nacional } \\
\text { Ministerio de } \\
\text { Desarrollo Social }\end{array}$ \\
\hline 36 & $3 / 2 / 2017$ & Sede CGT & $\begin{array}{l}\text { Barrios de Pie, } \\
\text { CCC y CTEP }\end{array}$ & $\begin{array}{l}\text { Acompañamiento } \\
\text { de anuncio de } \\
\text { plan de lucha de } \\
\text { la CGT }\end{array}$ & CGT & $\begin{array}{l}\text { Defensa de } \\
\text { "sectores agredidos } \\
\text { por la política } \\
\text { económica" }\end{array}$ & Gobierno nacional \\
\hline 37 & $\begin{array}{l}21 / 2 / \\
2017\end{array}$ & $\begin{array}{l}\text { Puente } \\
\text { Pueyrredón, } \\
\text { Congreso, } \\
\text { Retiro, } \\
\text { Obelisco }\end{array}$ & $\begin{array}{l}\text { Barrios de Pie, } \\
\text { Movimiento } \\
\text { Evita, CCC }\end{array}$ & $\begin{array}{l}\text { Ollas populares } \\
\text { y posterior } \\
\text { movilización al } \\
\text { Obelisco }\end{array}$ & & $\begin{array}{l}\text { Oposición a } \\
\text { recorte en planes } \\
\text { sociales (según } \\
\text { organizaciones } \\
20000, \text { según } \\
\text { gobierno } 7000 \text { ) }\end{array}$ & $\begin{array}{l}\text { Ministerio de } \\
\text { trabajo, Gobierno } \\
\text { nacional }\end{array}$ \\
\hline 38 & 23/2/2017 & Obelisco & $\mathrm{CCC}$ & $\begin{array}{l}\text { Movilización } \\
\text { y corte en el } \\
\text { Obelisco }\end{array}$ & & $\begin{array}{l}\text { Oposición a } \\
\text { recorte en planes } \\
\text { sociales (misma } \\
\text { demanda de arriba) }\end{array}$ & $\begin{array}{l}\text { Ministerio de } \\
\text { trabajo, Gobierno } \\
\text { nacional }\end{array}$ \\
\hline 39 & $3 / 3 / 2017$ & Sede CGT & $\begin{array}{l}\text { Barrios de pie / } \\
\text { CCC / CTEP }\end{array}$ & $\begin{array}{l}\text { Acompañamiento } \\
\text { de anuncio de } \\
\text { plan de lucha de } \\
\text { la CGT }\end{array}$ & CGT & $\begin{array}{l}\text { Enmarcado en } \\
\text { acuerdo sobre } \\
\text { reclamos de CGT } \\
\text { y movimientos al } \\
\text { gobierno }\end{array}$ & Gobierno nacional \\
\hline 40 & 11/3/2017 & & $\begin{array}{l}\text { Barrios de pie / } \\
\text { CCC / CTEP }\end{array}$ & $\begin{array}{l}\text { Anuncio de } \\
\text { movilizaciones }\end{array}$ & & $\begin{array}{l}\text { Efectiva } \\
\text { implementación } \\
\text { de ley de } \\
\text { emergencia social }\end{array}$ & Gobierno nacional \\
\hline 41 & 15/3/2017 & $\begin{array}{l}\text { Ministrio de } \\
\text { Desarrollo } \\
\text { social }\end{array}$ & $\begin{array}{l}\text { Polo obrero } \\
\text { (FOL) }\end{array}$ & $\begin{array}{l}\text { Acampe frente } \\
\text { a ministerio de } \\
\text { desarrollo social } \\
\text { en la } 9 \text { de julio }\end{array}$ & & $\begin{array}{l}\text { Participación en } \\
\text { programas de } \\
\text { empleo }\end{array}$ & Gobierno nacional \\
\hline 42 & 15/3/2017 & $\begin{array}{l}\text { Corrientes y } \\
\text { Callao } \\
\text { Puente } \\
\text { Pueyrredón } \\
\text { Autopista La } \\
\text { Plata }\end{array}$ & $\begin{array}{l}\text { Barrios de pie / } \\
\text { CCC / CTEP }\end{array}$ & Cortes de calle & & $\begin{array}{l}\text { Efectiva } \\
\text { implementación } \\
\text { de ley de } \\
\text { emergencia } \\
\text { social }\end{array}$ & Gobierno nacional \\
\hline 43 & $30 / 3 / 2017$ & $\begin{array}{l}\text { Plaza de } \\
\text { Mayo }\end{array}$ & $\begin{array}{l}\text { Barrios de pie / } \\
\text { CCC / CTEP }\end{array}$ & $\begin{array}{l}\text { Acompañamiento } \\
\text { a la movilización } \\
\text { de la CTA a Plaza } \\
\text { de Mayo }\end{array}$ & $\begin{array}{l}\text { CTA (las dos) } \\
\text { UOM } \\
\text { Corriente } \\
\text { Federal }\end{array}$ & $\begin{array}{l}\text { Fin de despidos y } \\
\text { suspensiones } \\
\text { Cambios en } \\
\text { el "rumbo } \\
\text { económico" }\end{array}$ & Gobierno nacional \\
\hline 44 & $5 / 4 / 2017$ & $\begin{array}{l}\text { Ministrio de } \\
\text { Desarrollo } \\
\text { social }\end{array}$ & $\begin{array}{l}\text { Agrupaciones Ana } \\
\text { María Villarreal, } \\
\text { Resistencia } \\
\text { Popular, La } \\
\text { Falcone y otras } \\
\text { cuatro }\end{array}$ & $\begin{array}{l}\text { Corte de la } 9 \\
\text { de julio frente } \\
\text { al Ministerio de } \\
\text { desarrollo social }\end{array}$ & & $\begin{array}{l}\text { Demandas en } \\
\text { relación al PAT }\end{array}$ & Gobierno nacional \\
\hline
\end{tabular}




\footnotetext{
${ }^{1}$ Una versión preliminar y resumida de este artículo fue presentada en la IV Conferência Internacional Greves e Conflitos Sociais, São Paulo, 2018 y en las XI jornadas de economía crítica, Santa Fe, 2018. Agradecemos enormemente a Julián Rebón por la lectura atenta de una versión preliminar.

${ }^{2}$ En el decreto de reglamentación de la Ley de Emergencia Social (159/2017) se entiende por Economía Popular toda actividad creadora y productiva asociada a mejorar los medios de vida de actores de alta vulnerabilidad social, con el objeto de generar y/o comercializar bienes y servicios que sustenten su propio desarrollo o el familiar.

${ }^{3}$ A lo largo del trabajo se harán breves referencias acerca de esta experiencia. En torno a la inclusión de referentes de las organizaciones sociales a la gestión estatal cf. Perelmiter (2016).

${ }^{4}$ Las primeras semanas del gobierno de Macri estuvieron marcadas por el levantamiento de una serie de controles a la compra-venta de divisas. La devaluación resultante, sumada a la remoción o baja de aranceles a la exportación de productos primarios, tuvo especial repercusión sobre el precio de los alimentos -con incrementos que habrían rondado el 65\% en el caso de las carnes (Varesi 2016).

${ }^{5}$ Por su originalidad como tentativa de organización gremial la CTEP ha sido profusamente indagada por la academia. Entre los trabajos existentes, se puede mencionar Abal Medina (2016); Bruno, Coelho y Palumbo (2017; Muñoz, (2019); Natalucci (2019).

${ }^{6}$ La CTA tiene una organización compleja, incluyendo sindicatos estructurantes (ATE y CTERA) pero también federaciones que exceden el ámbito gremial. Asimismo, a diferencia de la CGT, acepta la afiliación directa. Acerca de las particularidades de la CTA cfr Armelino (2005, 2007); Retamozo y Morris (2015). Esta central mantuvo su unidad durante más de 15 años pero a fines de 2010 se dividió en dos grupos diferentes. La CTA de los Trabajadores (CTA-T) y la CTA Autónoma (CTA-A). Las divergencias se vincularon al tipo de la relación a sostener con el Estado.

${ }^{7}$ Resulta adecuado incluir los aportes de Cefaï en torno a este aspecto. El autor afirma que si bien por mucho tiempo se ha entendido la acción colectiva desde una lucha frontal entre el establishment y los outsiders, actualmente la investigación se fue desplazando hacia otras modalidades de vinculación con el gobierno del estado, incluyendo dinámicas de participación y negociación política (2008:145).

${ }^{8}$ Los acampes son acciones de protestas de larga duración; su génesis se remonta a los cortes de ruta efectuados para mediados de la década de 1990 sobre la ruta 3 en La Matanza. La particularidad de estos nuevos acampes -que ya estuvieron presentes en las jornadas de lucha por la demanda del Programa Argentina Trabaja- es que trasladan la acción al centro mismo de la ciudad, produciendo un quiebre en la movilidad del espacio capitalino (Maneiro 2015). ${ }^{9}$ El CEPSSC propuesto incluía 5 miembros, 3 en representaciones de las organizaciones -que debían formar parte de un registro específico- y 2 representando el Poder Ejecutivo Nacional.

${ }^{10}$ Juan Carlos Schmidt integraba el triunvirato directivo de la CGT. Paula Abal Medina describe la trayectoria de este triunviro como un elemento nodal para comprender el singular y novedoso vínculo de la cúpula de la CGT con las demandas de las organizaciones de la economía popular (Abal Medina 2017).

${ }^{11}$ Hubo otros antecedentes respecto de la participación en consejos de implementación de políticas sociales. El más relevante fue el que se instauró con el programa Jefes y Jefas de Hogar Desocupados (PJJHD) en 2002, en plena crisis con el gobierno de Eduardo Duhalde.
} 


\section{Referencias bibliográficas}

Abal Medina, Paula (2016) "Los trabajadores y sus organizaciones durante los gobiernos kirchneristas”. Nueva Sociedad, 264: 72-86.

Abal Medina, Paula (2017) “Movilización y Reunificación Sindical”. Agencia Paco Urondo. https://www.agenciapacourondo.com.ar/relampagos/movilizacion-y-reunificacion. Accesado el 19 de agosto de 2020.

Armelino, Martín (2005) “Resistencia sin integración: protesta, propuesta y movimiento en la acción colectiva sindical de los “90. El caso de la CTA”. En F. Naishtat et al. (comps.). Tomar la palabra. Estudios sobre protesta social y acción colectiva en la Argentina contemporánea. Buenos Aires, Argentina: Prometeo, pp. 75-311.

Armelino, Martín (2004) "Algunos aspectos de la acción colectiva y la protesta en la CTA y el MTA”. Revista de Estudios Sobre Cambio Social, 15: 5-11.

Balinotti, Nicolás "La CGT acordó con piqueteros y avanza hacia un paro general". Diario La Nación, 8/9/2016).

Bruno, D., R. Coelho y M.M. Palumbo (2017) "Innovación organizacional e institucionalización conflictiva de las organizaciones de la economía popular. El caso de la Confederación de trabajadores de la economía popular (CTEP)". Argumentos. Revista de Crítica Social, 19: 90-119.

Cefaï, Daniel (2011) “Diez propuestas para el estudio de las movilizaciones colectivas. De la experiencia al compromiso". Revista de Sociología (Universidad de Chile) 26:137-166.

Corrali, Damián y Joaquín Forresti (2018) "Las coaliciones legislativas durante el gobierno de Cambiemos. Un estudio exploratorio”. Ensambles, 9: 17-40.

Etchemendy, Sebastián y Collier, Ruth Berins (2007) "Golpeados pero de pie: resurgimiento sindical y neocorporativismo segmentado en Argentina (2003/2007)". Politics and Society, 35, 3: 145-192.

Forni, Pablo Floreal (2019) “"Artesanos de la unidad' : misioneros de Francisco y los movimientos sociales en tiempos macristas”. Revista Estado y Políticas Públicas, 13:201-208.

Gradin, Agustina (2016) La participación política de las organizaciones de desocupados en el Estado nacional durante el periodo 2003-2009. La experiencia del Movimiento Barrios de Pie: sus límites y potencialidades. Tesis Doctoral, Universidad de Buenos Aires. 
Gradin, Agustina (2017) "Protagonismo y militancia: el estilo de gestión del movimiento barrios de pie en el ministerio nacional de desarrollo social, Argentina 2004-2009”. Collectivus, 2: 141-161.

Hopp, Malena (2017) "Transformaciones en las políticas sociales de promoción de la economía social y del trabajo en la economía popular en la Argentina actual". Cartografías del Sur, 6: 19-41.

Hudson, Juan Pablo (2018) "Políticas públicas de promoción de la autogestión cooperativa de la Alianza Cambiemos”. Revista Perspectivas de Políticas Públicas, 15: 173-205.

Hudson, Juan Pablo (2020) "La representación de los trabajadores informales: el Triunvirato de San Cayetano". Temas y Debates, 39: 35-58.

Ladrón de Guevara, Federico (2016) “La celebración de San Cayetano. Con más fila y menos plata". Clarín 7 de agosto.

Longa, Francisco. (2016) ¿Entre la autonomía y la disputa institucional? El dilema de los movimientos sociales ante el Estado. Los casos del Frente Popular Darío Santillán y el Movimiento Evita (Argentina, 2003-2015). Tesis Doctoral, Universidad de Buenos Aires.

Longa, Francisco (2019) Historia del Movimiento Evita, Buenos Aires, Argentina: Siglo XXI Editores.

Maneiro, María (2012) Encuentros y desencuentros. Estado, gobiernos y movimientos de trabajadores desocupados, Buenos Aires: Biblos.

Maneiro, María (2015) “Tiempos y espacios en disputa. Un modelo analítico para analizar la reaparición de las protestas urbanas de los movimientos de trabajadores desocupados". Quid 16, Buenos Aires, 5: 151-169.

Maneiro, María (2018) "La lucha de las organizaciones de trabajadores desocupados en los últimos años del kirchnerismo. Análisis del proceso de protesta ligado al Programa Argentina Trabaja”. Revista Sociohistórica. Cuadernos del CISH, La Plata, 42:1-30.

Muñoz, María Antonia (2019) "Voluntades populares, voluntades laborales. El caso de la Confederación de los Trabajadores de la Economía Popular”. Trabajo y Sociedad, 32: 479-510.

Natalucci, Ana (2019) “¿Superando la fragmentación? Un análisis de las estrategias de articulación entre la CGT y la CTEP (2009-2017)”. Astrolabio, Nueva época, 23: 169-197. 
Perelmiter, Luisina (2016) Burocracia Plebeya. La trastienda de la asistencia social en el Estado Argentino. Buenos Aires: UNSAM Edita.

Pérez, Verónica y Julián Rebón (2012) Las vías de la acción directa, Buenos Aires: Aurelia Rivera.

Rebón, Julián (2019) “La política en las calles”. Revista de Ciencias Sociales 32 (44) 15-42.

Retamozo, Martín y María Belén Morris,(2015) “Sindicalismo y política. La Central de Trabajadores de la Argentina en tiempos kirchneristas". Estudios sociológicos, 97: 63-87.

Svampa, Maristella y Sebastián Pereyra (2009) Entre la ruta y el barrio: la experiencia de las organizaciones piqueteras. Buenos Aires: Editorial Biblos.

Tilly, Charles (1978) From Mobilization to Revolution. Londres, Reino Unido: Mc. Graw Hill.

Tilly, Charles (2000) “Acción colectiva”. Apuntes del CECYP, 6: 9-32.

Tilly, Charles (2002) “Events as Theories”. Sociological Theory, 20: 348-354.

Varesi, Gastón Ángel (2016) “Tiempos de restauración: balance y caracterización del gobierno de Macri en sus primeros meses”. Realidad económica, 302: 6-34.

\section{Documentos oficiales}

Proyecto de Ley de Emergencia Social

Ley 27.345 de Emergencia social

Decreto 159/2017

\section{Cómo citar este artículo}

Maneiro, María y Javier Núñez (2021) “Acción colectiva, negociaciones y alianzas tras la Ley de Emergencia Social”. Revista Perspectivas de Políticas Públicas vol. 10 No 20: 429-457 